\title{
Antenatal Care Visits and Early Detection of Pre-eclampsia among Pregnant Women
}

\author{
Dini Rima Fadilah, Shrimarti Rukmini Devy \\ Department of Health Promotion and Behavior Science, Airlangga University, Indonesia
}

\begin{tabular}{|c|c|}
\hline Article Info & ABSTRACT \\
\hline Article history: & \multirow{8}{*}{$\begin{array}{l}\text { The death of pregnant women is still the world's attention in the field of } \\
\text { health. The SDG's indicator provides one of the goals in the health field. The } \\
\text { target to be achieved is a global maternal mortality ratio of less than } \\
70 / 100,000 \text { live births by } 2030 \text {. According to WHO, preeclampsia is one of } \\
\text { the leading causes of maternal death in the world, including Indonesia. East } \\
\text { Java Province with the highest ranking in Indonesia. One of the cities in East } \\
\text { Java which is the leading contributor to preeclampsia is Surabaya with } 16 \\
\text { cases in } 2016 \text {. The government carries out the treatment to reduce maternal } \\
\text { mortality due to preeclampsia through antenatal care. This study aimed to } \\
\text { analyze antenatal care visits for early detection of preeclampsia. The method } \\
\text { in this research is qualitative research method with data retrieval technique } \\
\text { using in-depth interview. Based on the results of research antenatal care } \\
\text { visits have an effect on early detection of preeclampsia. Pregnant women } \\
\text { who regularly make antenatal visits can prevent possible dangers of } \\
\text { pregnancy as early as possible. So the maternal mortality rate (MMR) due to } \\
\text { pre-eclampsia can be decreased. }\end{array}$} \\
\hline Received Jul 31, 2018 & \\
\hline Revised Nov 6, 2018 & \\
\hline Accepted Nov 15, 2018 & \\
\hline Keyword: & \\
\hline Antenatal care & \\
\hline Pre-eclampsia & \\
\hline Pregnant women & \\
\hline
\end{tabular}

Copyright $(0) 2018$ Institute of Advanced Engineering and Science. All rights reserved.

\section{Corresponding Author:}

Dini Rima Fadilah,

Department of Health Promotion and Behavior Science,

Airlangga University,

Mulyorejo St, Surabaya, East Java 60115, Indonesia.

Email: dinirimafadilah089@gmail.com

\section{INTRODUCTION}

The birth of a healthy and quality generation can not be separated from efforts to maintain Mother and Child Health (KIA) and reduce maternal and child mortality. Until now the Maternal Mortality Rate (MMR) remains a priority issue in the world. According to WHO maternal mortality is the incidence of death of a woman during pregnancy or within 424 days after the end of pregnancy. Regardless of gestational age and the action taken to terminate the birth, be it a cause related to pregnancy or not (other factors) [1], [2]. The highest maternal mortality in 2015 occurs in developing countries with a maternal mortality ratio of 239 per 100,000 live births compared with developed countries of 12 per 100,000 live births. The high number of maternal deaths received attention from a United Nation (PBB). SDG's (Sustainable Development Goals) is a policy endorsed by PBB as a goal of sustainable development. One of the targets of SDG's in the health sector to be achieved is the ratio of global maternal deaths to less than 70 per 100,000 live births by 2030 .

Indonesia is a developing country with high maternal mortality cases. Ministry of Health data of 2016 mentions the trend of the development of maternal mortality cases in Indonesia in 1991-2015. It is known that the number of maternal deaths in Indonesia decreased from 1991 to 2007. Cases increased in 2012 by 359/100,000 live births. The case again declined to 305/100,000 live births by 2015 [3]. The highest number of maternal deaths occurred in Java Island, West Java followed by Central Java and East Java. Maternal Mortality Rate (MMR) in East Java Province is still below the set target despite decreasing every year [8]. 
Health profile data of East Java Province shows that Surabaya has the highest Maternal Mortality Rate (AKI) in East Java [4]. The number of cases of maternal deaths in Surabaya in 2014 was 90.19/100,000 live births, 2015 of 87.36/100,000 live births, and 2016 again declined to 85.72/100,000 live births. It is known that most deaths occur in the productive age of 20-34 years. Number of Cases and Causes of Pregnant, Maternity and Post-partum Death of Surabaya City 2014-2016 shown in Table 1.

Table 1. Number of Cases and Causes of Pregnant, Maternity and Post-partum Death of Surabaya City 2014-2016

\begin{tabular}{|c|c|c|c|c|c|}
\hline \multirow{2}{*}{ No. } & \multirow{2}{*}{ Cause Of Death } & \multicolumn{3}{|c|}{ Year } & \multirow{2}{*}{ Total } \\
\hline & & 2014 & 2015 & 2016 & \\
\hline 1. & Bleeding & 10 & 13 & 7 & 30 \\
\hline 2. & Preecampsia / Eclampsia & 11 & 7 & 14 & 32 \\
\hline 3. & Infection & 0 & 0 & 0 & 0 \\
\hline 4. & Heart Disease & 2 & 3 & 1 & 6 \\
\hline 5. & HIV & 1 & 0 & 1 & 2 \\
\hline 6. & Pulmonary TB & 1 & 2 & 5 & 8 \\
\hline 7. & Hepatitis & 1 & 0 & 0 & 1 \\
\hline 8. & Others & 13 & 13 & 9 & 35 \\
\hline & Total & 39 & 38 & 37 & 114 \\
\hline
\end{tabular}

Based on the above table it is known that preeclampsia is the highest cause of maternal death cases in Surabaya. While bleeding became the second highest cause of maternal death. Other causes of death include amniotic fluid embolism, diabetes mellitus, urosepsis, kidney, hyperthyroidism, lupus, pulmonary edema, and pleural effusion. Until now not known exactly the cause of preeclampsia in pregnancy. Preeclampsia is also called "disease of theory" because it has not been elucidated using a single factor or theory that can only describe the full range of clinical manifestations [6].

The Government made efforts to reduce maternal mortality rate (MMR) through increased access to health services. According to the Law of the Republic of Indonesia No.36 Year 2009 on health article 126 paragraph (1) said that health services are aimed at maintaining maternal health in order to be able to give birth to a healthy and quality generation and to reduce maternal mortality rate [7]. Ministry of Health RI in 2004 made a policy to overcome and accelerate efforts to decrease maternal mortality (MMR) and infant mortality (IMR). The policy refers to the strategic "Four Pillar Safe Motherhood" interventions that include family planning, Antenatal Care (ANC), clean and safe deliveries, and essential obstetric care [8]. One of the four pillars that can cope with the problem of preeclampsia is antenatal care. Maternal intensity in antenatal care visit influential to early detection of pregnancy risk by health professionals Pregnant women who routinely check their pregnancy in health facility will be more quickly get treatment and treatment if found signs of danger in pregnancy

\section{RESEARCH METHOD}

This research uses qualitative research type with in-depth interview technique. Interview results are described in descriptive form. It is used to reflect or describe the condition of the object under study in according to the situation with the time of the study [9]. Source of data comes from primary data and secondary data. Primary data were obtained by interviews to key informants and supporting informants. While secondary data obtained from health profile and data of puskesmas. Sources of the main informants of this study were mothers who performed pregnancy and delivery pregnancy in October 2017 to March 2018 in the part Surabaya. While the supporting informant is midwife in that area.

Determination of informants using purposive sampling technique that is using the sampling unit in according with the criteria that have been established based on research [10]. There were four pregnant women who became the main informants in this study. The research instrument used was interview and researcher by self. Data obtained then analyzed by content analysis technique. The flow used to analyze data is data reduction, data presentation, and deduction of conclusions. Triangulation data is also applied to compare and make sure the data obtained is accurate. Triangulation used in this study is triangulation of data sources with the same technique but different informants [10]. Data source in triangulation of data comes from supporting informant that is health center midwife. 


\section{RESULTS AND DISCUSSION}

\subsection{Pre-eclampsia}

Preeclampsia is a condition of rising maternal blood pressure when pregnant because of protein in the urine [11]. This disorder often occurs in second or third trimester of pregnancy. If left unattended and will not get intensive care will result in the mother experiencing seizures and coma. Signs of pregnant women with preeclampsia are blurred vision, swelling/edema of the feet and face, and pain in the epigastrium. These signs can be immediately handled by health personnel if the mother visits antenatal care. Antenatal Care (ANC) is a pregnancy examination that aims to optimize the mental and physical health of pregnant women with a standard 10T. antenatal care with $10 \mathrm{~T}$ in question Weigh weight and height ukurn, measure blood pressure, determine/value of nutritional status, height of uterine fundus, Determine the presentation of fetal and fetal heart rate, Tetanus Toxoid, giving Tablet added blood, Test Laboratory, Special Management, and Speech Talk (counseling). The purpose of antenatal care is to control the health of mother and baby in the womb. In addition to early detection of complications that occur during pregnancy. Through antenatal examination health workers can know early on signs of danger of pregnancy. so the development of preeclampsia can be prevented properly [12].

\subsection{Antenatal care visits}

Antenatal Care Visits are visits of pregnant women to midwives or physicians as early as possible to obtain antenatal care/antenatal care. Antenatal visitation is also an effort that can be done for early prevention of preeclampsia. Pregnant women with a blood pressure check at the first visit will make it easier for health workers to do the treatment as early as possible. The government itself has made policies related to antenatal care programs. An antenatal care program policy sets the frequency of visits to be at least four times during pregnancy as shown in Table 2.

Table 2. Terms of Antenatal Visits

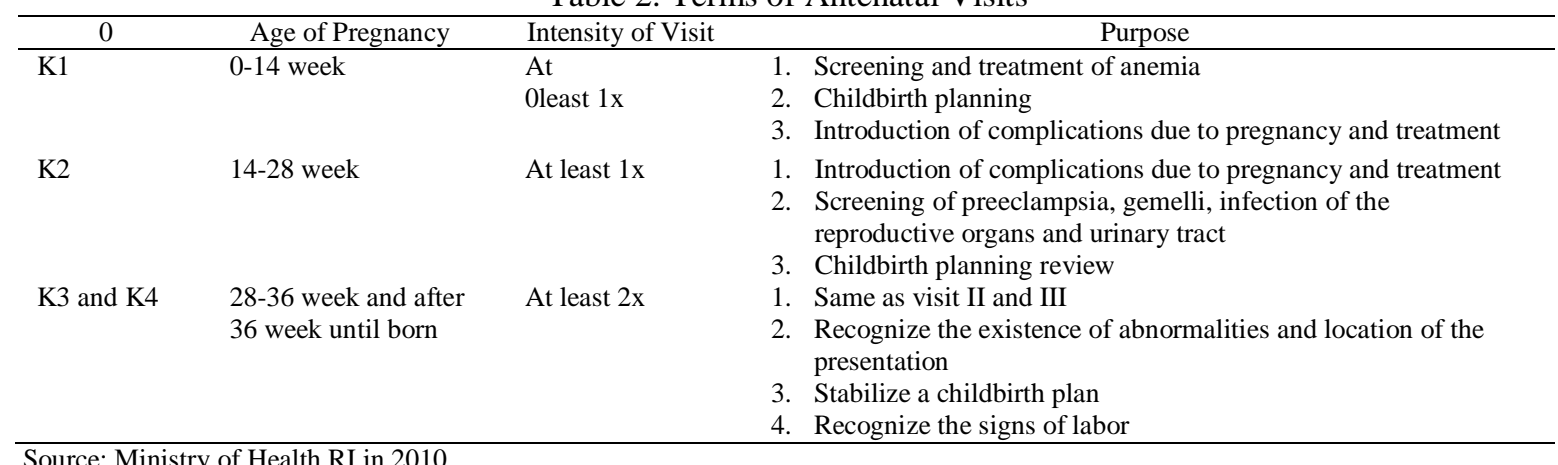

Source: Ministry of Health RI in 2010

Based on Table 2 it is known that the second trimester visit (K2) aims for early detection of preeclampsia. Even early detection of preeclampsia can be done from the first visit (K1) of the mother to the health service. This is also justified by the midwives of puskesmas X. According to the midwife, the maternal health center whose pregnancy check will receive antenatal service plus the ROT (Roll Offer Test) method as early detection of preeclampsia. This service is one of the quality indicator that X community health center wants to achieve and start running since April 2018. The technique of early detection of preeclampsia with ROT method is done simultaneously with blood tension examination. The difference lies in the position of the mother when the tension is done. ROT method of blood pressure in pregnant women performed on the tilts and supine with a grace period of 5 minutes. According to Tono (2014) ROT examination results are more accurate in detecting preeclampsia in second and third trimester pregnant women [13].

In addition, early detection of preeclampsia support is the result of laboratory and physical examination. The physical signs of pregnant women of preeclampsia are swelling of the feet, face, dizziness, and shortness of breath. Pregnant women with physical signs and laboratory results with albumin> 1 tested positive for preeclampsia. so it must be immediately referred to advanced facilities to get better service and more complete equipment. Here is the quote of research result with midwife of puskesmas.

"When visiting a midwife does not distinguish between pregnant women are risky or not at risk, which must be at least 1 time check at the health center will be checked with ROT. But if from the beginning have seen signs of preeclampsia such as high blood pressure, there is albumin in urine, 
facial expression and leg swelling, dizziness, and shortness of breath it will be done ROT each control. but if early detection has been detected preeklampsia will be given a referral to the hospital for further treatment" (midwife coordinator, 35 years old)

It is necessary to improve the service by health workers to informants. Increased quality of good service is expected to also increase the awareness and willingness of pregnant women to routinely conduct antenatal visits at health centers. In addition health services at health centers are also obtained for free because all actions will be financed by the government..

\subsection{Intensity of antenatal care visit to early detection of preeclampsia}

Antenatal care visits are indispensable for pregnant women, but the intensity of the visit also affects the condition of pregnancy. Mothers who do not regularly check their pregnancy will have a difference with the routine mother. Mothers who regularly visit antenatal will be easier to know the condition of pregnancy.

Table 3. Characteristic of Informant

\begin{tabular}{cccccc}
\hline \multirow{2}{*}{ Key Informant } & Initial & Age & K1 & Place of Antenatal Care Visit & K2 \\
\hline Informant 1 & SM & 33 & Hospital & Puskesmas & Hospital \\
Informant 2 & FM & 22 & Puskesmas & Private Midwife & Puskesmas \\
Informant 3 & RPB & 24 & Hospital & Puskesmas & Hospital \\
Informant 4 & FA & 26 & Private midwife & Puskesmas & Hospital \\
\hline
\end{tabular}

Based on the results of the research found that four informants have been doing antenatal visits at least once a month. Antenatal visits were conducted by informants at different health facilities. Visits K1 through K4 are conducted at both primary and secondary health facilities. Based on the table, the informant 4 checked her first trimester pregnancy on a private midwife. In contrast to informants 2 who until the third trimester did not make a visit to the hospital despite having received a reference. The informant claimed to be afraid if the hospital's medical personnel did medical treatment. Here is the quote of research with informant.

"When the midwife gave me a referral to the hospital I refused for fear and wanted to discuss with my parents. Then, suddenly I was cramped and unconscious and my husband took me to the hospital." (Informant 2, 22 years old)

The actions of the two informants to delay the visit to the hospital are very risky. The informant experienced a seizure due to delayed treatment of the health facility. If it is not addressed soon will cause death to the mother. Delays of informants to visit in advanced facilities are also due to lack of knowledge related to the dangers of preeclampsia. So the informant underestimates the reference given by the midwife. In addition two out of four informants made their first antenatal care visit at the hospital and only one informant performed $\mathrm{K} 1$ at the puskesmas. As for $\mathrm{K} 3$ and $\mathrm{K} 4$, three informants made an antenatal care visit (ANC) to the hospital because they got a referral from the puskesmas. The referral was given when the informant tested positive for preeclampsia The aim is that pregnant women preeclampsia get intensive treatment to prevent the risk of complications in pregnancy. According to informant 1 (33 years) second trimester antenatal examination done at puskesmas because having service with BPJS. Here is the quotation of research result to informant.

"From the beginning of pregnancy until the age of 4 months of pregnancy I did antenatal at IBI hospital. Then move to puskesmas to get BPJS financing. " (Informant 1, 33 years old)

This is in contrast to the 3 informants who from the first trimester of pregnancy until the third trimester had antenatal visits at the hospital. However, the informant 3 began to check her pregnancy at the age of three months of pregnancy because of advice from parents. The enthusiasm and intent of the informant 3 to make an antenatal visit is still lacking. This can happen because of the lack of knowledge of pregnant women about the importance of antenatal examination. Here is the quotation of research result to informant.

"I started an antenatal visit from the age of 3 months of pregnancy for advice from parents. At first I did not intend to check because I felt there was no interruption in pregnancy." (Informant 3, 24 years old)

However, maternal compliance in antenatal visits has been routine. This is evidenced by the intensity of informants who always perform antenatal checks at least once a month. However, three out of four informants are still unaware of what benefits pregnant women can get during an antenatal visit. They only know that antenatal care is useful to control the condition of the baby in the womb. Even informants do not know the term preeclampsia. They know this when expressed positive preeclampsia by health personnel. Here is the quotation of research result to informant. 
"I have never heard of the term preeclampsia, I just found out when the midwife check the condition of my pregnancy. The midwife then told me that my blood pressure was high." (Informant 2, 22 years old)

"I do not know about preeclampsia, just got information that high blood pressure since early pregnant mbak, blood tension is always increasing every month. This also happened when I was pregnant with my first child." (Informant 1, 35 years old)

While one of four informants who tested positive for preeclampsia is very concerned about pregnancy. Since it was stated positive preeclampsia informants are very healthy and routinely conduct antenatal visits. Informants also take time to counsel with health workers when conducting antenatal screening. Here is the quotation of research result to informant.

"Every time I do antenatal care I always consult with doctors like food that should not be eaten, and how to keep blood pressure from getting higher." (Informant 4, 26 years old)

Any maternal antenatal visit is useful for detecting danger signs in pregnancy in each trimesters [14]. Good knowledge of high-risk pregnancy will make it easier for mothers to recognize and prevent early in pregnancy problems. The higher the knowledge the mother may be perceived that antenatal examination is important to avoid high risk factors and problems in pregnancy [15]. Mothers can also prevent and treat early. So the risk of complications in pregnancy and the incidence of severe preeclampsia can be suppressed as early as possible. It also can not be separated from the role of health personnel in performing antenatal care (ANC). Providing information about preeclampsia by health personnel will make pregnant women more motivated to make antenatal care visits. According to Kurnianingsih the motivation of pregnant women in performing antenatal examination in health facility increased after health counseling [16]. This then makes pregnant women want to always know the development of pregnancy. When a mother is motivated to perform an antenatal examination, the visits will be more routine than before.

Based on the results of the study note that pregnant women who regularly visit antenatal and pregnancy care still have the potential to experience preeclampsia. So that pregnant women who do not regularly visit antenatal will be at greater risk of experiencing preeclampsia. This is because antenatal care serves to detect the possibility of danger in pregnancy as early as possible. If the dangers of pregnancy can be detected immediately, health workers will be easier to prevent and treat. According to Aprina [17] the history of Antenatal Care (ANC) is the most influential factor on the risk of incidence of hypertension in pregnancy [17]. In line with the Saraswati's study that pregnant women who are not routinely antenatal care are at risk of preeclampsia 17,111 times greater [18]. Meanwhile, according to Nur [19] pregnant women who did not make antenatal visits risk 7,933 times affected by preeclampsia compared with mothers who visited antenatal> 2 times [19]. In contrast to Faiqoh's study [20] that there is no link between antenatal care visits and the incidence of preeclampsia [20]. This is in line with the Yuniarti's study [21] that antenatal care is not associated with preeclampsia. So to help identify and prevent the risk of preeclampsia, health workers can increase the motivation of pregnant women. If maternal motivation for antenatal visits is high, then early detection of preeclampsia can be performed by health personnel well [21].

\section{CONCLUSION}

Based on the results and discussion of research that has been done in Puskesmas X can be concluded that there is influence of antenatal care visit to early detection of preeclampsia. Intensity of antenatal care visits is influenced by the level of knowledge of the mother. Pregnant women who get pregnancy-related information and pregnancy signs will have a higher level of knowledge. The high knowledge of mothers can change the perception of pregnant women with the aim of the importance of antenatal care visits. This makes the mother moved to regularly check her pregnancy in order to do prevention as early as possible.

The more pregnant women are aware and routine antenatal visits, the easier the health professionals record the history of maternal pregnancy every month. So that signs of danger in pregnancy one of them preeclampsia can be detected quickly. Health workers can also perform medical treatment to minimize the occurrence of complications and death for the mother with a diagnosis of preeclampsia. Surely this antenatal care visit is very helpful mother and health personnel to make early detection of preeclampsia. Mothers who regularly make antenatal visits will be able to prevent the possibility of danger in pregnancy as early as possible. So the Maternal Mortality Rate (MMR) due to preeclampsia can be decreased.

\section{ACKNOWLEDGEMENTS}

This manuscript was written in fulfillment of the requirement to obtain the Bachelor degree of Public Health in Universitas Airlangga. The authors declare that there is no conflict of interest regarding publication of this article. 


\section{REFERENCES}

[1] World Health Organization., Maternal Mortality. World Health Organization, 2014.

[2] World Health Organization., Trends in Maternal Mortality 1990-2015. Geneva 27, Switzerland: WHO Press, Wolrd Health Organization, 20 Avenue Appia, 1211, 2015.

[3] Ministry of Health RI., Performance Report of the 2016 Directorate General of Public Health. Jakarta, 2016.

[4] East Java Provincial Health Office. Health Profile of Surabaya City Health Office in 2016. Surabaya: East Java Provincial Health Office, 2016.

[5] Surabaya City Health Office. Health Information Data of Surabaya City Health Office in 2016. Surabaya: Surabaya City Health Office, 2016.

[6] Manuaba, IBG., Obstetrics, Gynecology and Family Planning Edition 2. Jakarta: EGC, 2010.

[7] Law of the Republic of Indonesia Number 36 of 2009. About health. 13 October 2009. State Gazette of the Republic of Indonesia Year 2009 Number 1441.

[8] Ministry of Health RI., KIE Safe Motherhood di Indonesia. Jakarta: Depkes RI, 2004.

[9] Ibrahim, M.A., Qualitative Research Methodology Research Guide and Examples of Qualitative Proposals. Pontianak. National Library: Catalog in Publications, 2015.

[10] Sugiyono., Educational Research Methodology. Bandung: Alfabeta, 2012.

[11] Rahmasari, Gartika. 9 Months 10 Special and Amazing Days during Pregnancy. Jakarta: New Agogos, 2012.

[12] Ministry of Health RI., Guidelines for Antenatal Services in the Working Area of Puskesmas. Jakarta: Depkes RI, 2010.

[13] Tono, S.F.N., "Differences in Preeclampsia Events between Roll Over Test (ROT) and Conventional Examination in Trimester II and III Pregnant Women in 2014.” Stikes Journal. Downloaded from ejournal.stikeswilliambooth .ac.id on June 4, 2018 at 21.44, 2014.

[14] Suryani., Utama, S.Y., Suryanti, Y., "Relationship between Knowledge and Family Support with Antenatal Care Visits for Pregnant Women in the Working Area of the Puskesmas Olak Kemang, Jambi City in 2015." Bahana Journal of Public Health. Vol. 1. No. 1. May 2017: 8-17, 2017.

[15] Qudriani, M., Hidayah, S.N., "Perception of Pregnant Women About High Risk Pregnancy with Adherence to Doing Antenatal Care in Begawat Village, Bumijawa District, Tegal Regency, 2016." 2nd National Seminar on Applied Science and Technology (SENIT) 2017. May 2017. Tegal-Indonesia: 197-203, 2017.

[16] Kurnianingsih, I., Suratini. Impact of Preeclampsia Counseling on Motivation for ANC Visit to Pregnant Women at Banguntapan I Health Center, Bantul. Publication manuscript. Thesis, Aisyiyah University Yogyakarta, 2017.

[17] Aprina, Dewi N.I., "Factors for Mild Preeclampsia in the Working Area of Inpatient Puskesmas Gedong Tataan Pesawaran District" Journal of Health, Volume VII, Number 2. August 2016: 314-322, 2016.

[18] Saraswati, N., Mardiana, "Risk Factors Related to Preeclampsia Occurrence in Pregnant Women (Case Study in Brebes District Hospital 2014)" Unnes Journal of Public Health, Vol. 5., April 2016: 90-99, 2016.

[19] Nur, A.F., Arifuddin, A., Risk Factors for Preeclampsia in Pregnant Women at Anutapura General Hospital in Palu City. Tadulako Health Journal. Vol. 3. No. 2. July 2017: 69-75, 2017.

[20] Faiqoh, E., Hendrati, L.Y., "Relation of Maternal, ANC, and Compliance Characteristics of Pregnant Women with Preeclampsia." Periodic Epidemiology Journal. Vol. 2. No. 2. May 2014:216-226, 2014.

[21] Yuniarti, F., Wilayati, W., Ivantarina, D., "Health Behavior Analysis and Risk Factors for Preeclampsia Events in Pregnant Women at Obstetrics Gynecology Polytechnic of Kediri District Hospital" Journal of Issues in Midwifery. March 2018. Vol. 1. No. 3: 1-17, 2018. 